\title{
Integrating alternative water sources in urbanised environments
}

\author{
M. Schwecke, B. Simmons, B. Maheshwari \& G. Ramsay \\ Co-operative Research Centre for Irrigation Futures, \\ School of Natural Sciences University of Western Sydney, Australia
}

\begin{abstract}
The need to use alternative sources of water for irrigation has arisen from the current shortages of potable water within Australia. As a result local governments are investigating alternative water sources (treated effluent, stormwater and groundwater) for irrigating urban playing fields and open spaces to cope with times of water shortages.

In this paper, using Manly Local Government as a case study, the quality of treated effluent, stormwater, groundwater and the receiving water was analysed, to determine the potential impacts of capturing and using these alternative sources on the local environment. Systems analysis was used to identify the connectivity between the various water sources.

It was observed that the injection of stormwater and effluent into the local water cycle could potentially pose a risk to the environmental, including ground and surface waters which are estuarine influenced systems. Stormwater was found to be of a variable quality and therefore requires constant monitoring to ensure no contamination events (such as road spill) enter the system. Groundwater salinity levels also required constant monitoring to prevent ingress of saline estuarine water. It also appears that as long as appropriate safeguards are put in place, the use of alternative water sources could help improve the local water cycle processes of urbanised catchments.
\end{abstract}

Keywords: environmental connectivity, environmental susceptibility, groundwater, stormwater, systems analysis, treated effluent, urbanised environments. 


\section{Introduction}

Continuing drought conditions in much of Australia has led to an increase in the overall demand for water in many of the major cities and towns across the country. As a result of the increased water demand, water restrictions have been imposed by the state government in most parts of Australia. In the Sydney Metropolitan Area water restrictions have been in place since October of 2003 [1]. As these water restrictions limit the amount of potable water that can be used to irrigate local playing fields, local government agencies have started to examine alternative water sources such as treated effluent, stormwater and groundwater to irrigate their urban playing fields as well as the open spaces (such as parks, trees and garden beds).

Manly Council is one such local government agency which has started to explore the use of alternative water sources for irrigation on urban playing fields and open spaces. The Manly Local Government Area (LGA) is located approximately 11 kilometres $(\mathrm{km})$ North-East of the Sydney Central Business District (CBD), within NSW. The LGA is approximately $15.14 \mathrm{~km}^{2}$ and includes 520 hectares of parks, reserves and other forms of open spaces representing 32 percent of the local area. Manly LGA is surrounded by $32.9 \mathrm{~km}$ of shoreline (Manly Lagoon to the North, Manly Beach to the East, and Middle Harbour to the South) [2] as seen in figure 1.

In response to increasing water shortages and bans on the use of potable supplies Manly Council and Manly Golf Club in 1998 [3] began investigation of alternative water sources to maintain their playing surfaces. This included the use of ground water, stormwater and treated effluent.

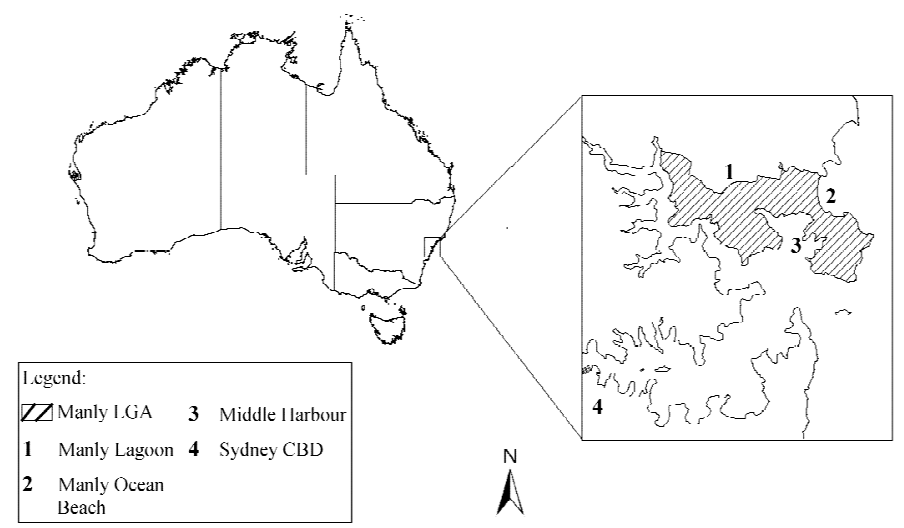

Figure 1: $\quad$ Location map of Manly [4].

\section{Research design}

In 2005 Manly Council commenced a joint research project with the University of Western Sydney and the Cooperative Research Centre for Irrigation Futures. The 
project was established to determine whether the use of alternative water sources such as stormwater, treated effluent and groundwater would affect the fragile environment of the receiving waterway (Manly Lagoon). The research study sites were Manly Golf Course and two surrounding playing fields - LM Grahams and Keirle Park, where the current use of groundwater and potable water will be supplemented with stormwater and treated effluent for irrigation use.

The current water sources for irrigation at the three sites vary, as do their size and water use (as seen in table 1).

Table 1: $\quad$ Water used to irrigate open spaces.

\begin{tabular}{|l|c|c|c|}
\hline Open Space & LM Grahams & Keirle Park & $\begin{array}{c}\text { Manly Golf } \\
\text { Course }\end{array}$ \\
\hline Ownership & Manly Council & $\begin{array}{c}\text { Manly } \\
\text { Council }\end{array}$ & Manly Golf Club \\
\hline Area (Ha) & $5.1 \mathrm{ha}$ & $1.6 \mathrm{ha}$ & $42.9 \mathrm{ha}$ \\
\hline $\begin{array}{l}\text { Source of Irrigation } \\
\text { Water }\end{array}$ & $\begin{array}{c}\text { Potable \& } \\
\text { Groundwater }\end{array}$ & Potable & Groundwater \\
\hline $\begin{array}{l}\text { Average Water Use } \\
\text { (ML/Year) }\end{array}$ & $7.21 \mathrm{ML} /$ Year & $3.74 \mathrm{ML} /$ Year & $218.4 \mathrm{ML} /$ Year \\
\hline $\begin{array}{l}\text { Average Water Use } \\
\text { (per ha) }\end{array}$ & $\begin{array}{c}1.41 \\
\mathrm{ML} / \mathrm{ha} / \text { year }\end{array}$ & $\begin{array}{c}2.34 \\
\mathrm{ML} / \mathrm{ha} / \text { year }\end{array}$ & $5.09 \mathrm{ML} / \mathrm{ha} / \mathrm{year}$ \\
\hline
\end{tabular}

From table 1, it is clear that the largest consumer of water is Manly Golf Course which uses 5.09ML of water per hectare per year to irrigate its course. It can also be seen that Manly Golf Course currently only uses one source of water for irrigation - groundwater. This source however has started to become unusable as over extraction appears to be drawing saline water from the nearby lagoon into the groundwater aquifer.

Manly Council has commenced a project in co-operation with Sydney Water and Manly Golf Club to utilise treated effluent at the nearby treatment plant and pipe this recycled water to the playing fields for irrigation use. As the treated effluent supply to the three study sites is still under the design phase, the quality data of the treated effluent was unavailable. On the other hand, the groundwater at the golf course and LM Grahams has been monitored for quality. The golf club has plans to use the stormwater entering its course, therefore past stormwater data gathered by Manly Council was sourced and analysed in the present study.

Between 2006 and 2007, the groundwater which Manly Golf Club uses to irrigate its golf course and Manly Council to irrigate its playing field (LM Grahams) was monitored for the quality of the groundwater. The main purpose of the monitoring was to see if the electrical conductivity (EC) (a measure of dissolved salt concentrations) levels were increasing with the use of the groundwater for irrigation.

In addition to the groundwater the receiving waterway Manly Lagoon was monitored to assess its water quality over a one year period (2006). Manly 
lagoon is one of the most polluted coastal lagoons on the east coast of Australia [5]; it is for that reason a very sensitive and fragile environment. The quality data from the lagoon was then compared to the Australian and New Zealand Environment Conservation Council (ANZECC) guidelines for the protection of aquatic ecosystems [6] to determine the health of the water way.

Stormwater data around Manly Golf Course and LM Grahams Reserve was collected through Manly Council's water cycle management team which have been monitoring the stormwater in Cemetery Creek (stormwater system which runs through Manly Golf Course) since 2005. The stormwater data was analysed for quality and also assessed against the irrigation guidelines [7].

Treated effluent to be used to irrigate the three sites, is regularly monitored by Sydney Water. The treated effluent is produced through a tertiary membrane treatment facility located within North Head Sewerage Treatment Plant (STP) one of the largest STP within Sydney, and which is owned and operated by Sydney Water [1]. Since the treated effluent is monitored by Sydney Water, water quality data for the effluent were not available for the present analysis. However, depending on the treatment, treated effluent can still retain high levels of nutrients and salt and needs to be accounted in the total water cycle management.

Systems analysis techniques allowed the formulation of detailed pictures of the current situation, through understanding the processes, structures and relationships with the environment [8]. Flood [8] explains that systems enable us to appreciate as well as 'sense out' the connections to the wider environment. Through utilising systems tools it allows the issues surrounding the use of these alternative water sources (treated effluent, stormwater and groundwater) to be investigated further. A picture of the current system was created to assess the response to different inputs and uses and to identify if the alternative water sources and the receiving environment could potentially contaminate one another.

\section{Results}

\subsection{Systems analysis}

In analysis of the Manly Golf Course system (incorporating LM Grahams Reserve and Keirle Park) the interconnections between the various alternative water sources were identified. Figure 2 illustrates these connections between the various alternative water sources within the system and identifies external influences that could cause potential problems to the receiving environment (Manly Lagoon). An example of this might involve the irrigated treated effluent overflowing into the lagoon. The effects that might occur could include eutrophication, loss of biodiversity and/or contamination. The systems diagram also illustrates the ease that pollutants can flow into the various components of the system if appropriate safeguards are not put into place.

Systems analysis was used to identify the potential problems that could affect the lagoon system including: increased nutrients in the soil (nutrient imbalance); 
increase in pollutants entering the lagoon water body; and salinity impacts on the soil and groundwater system. Although these problems/impacts from the use of alternative water sources in this fragile system were deemed as a minor risk to the system. However, if the risk is not monitored properly, the consequences to the receiving environment would be amplified and may impact of sustainability of the water resources in the area. However, of particular note is the connectivity between the stormwater, lagoon and groundwater which indicates that contamination can be transferred to groundwater either by overland flow or by groundwater ingress.

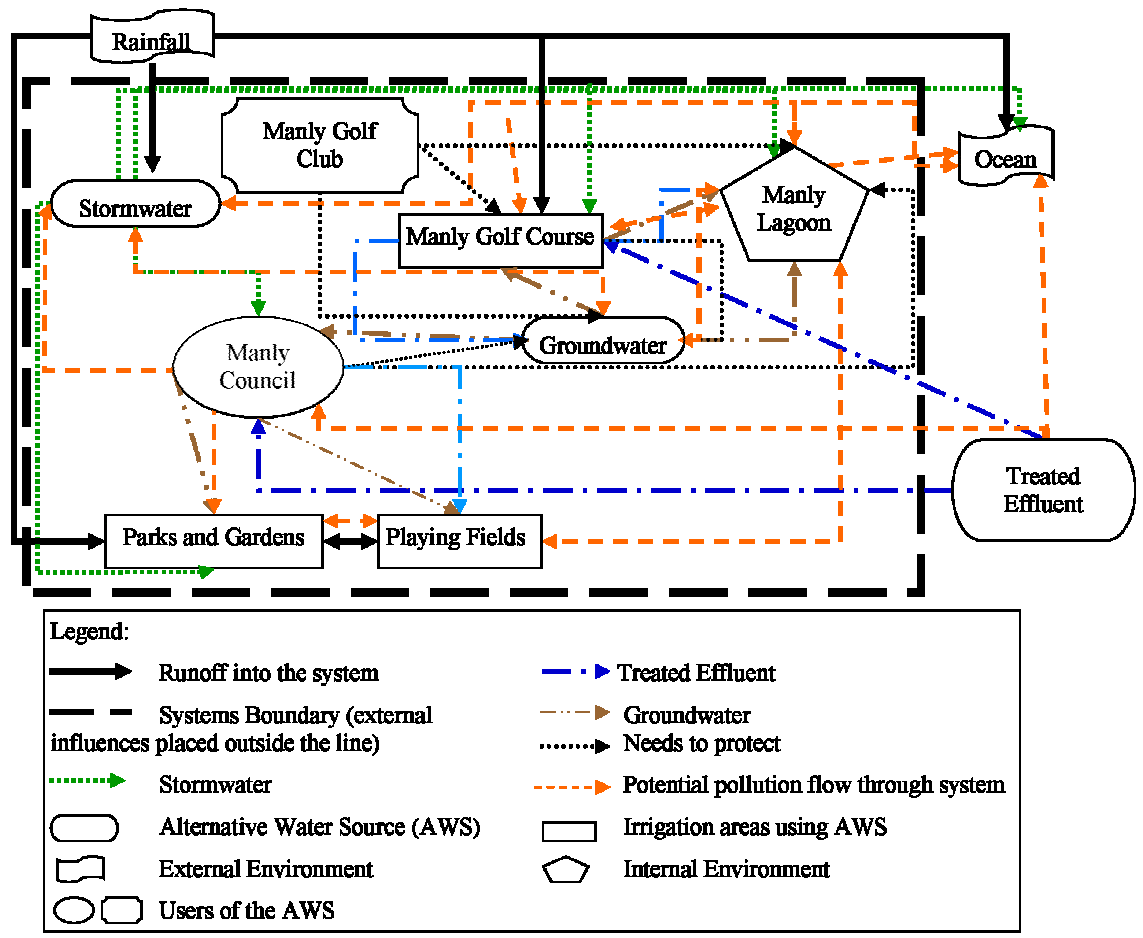

Figure 2: $\quad$ Manly Golf Course/Manly council water system.

\subsection{Groundwater Monitoring}

Monitoring of the groundwater that Manly Golf Club uses to irrigate the golf course in 2004 and 2006 showed that the EC levels were increasing the closer the location of the monitoring site to the Lagoon (as seen in figure 3). This increase suggests that the saline waters of Manly Lagoon are slowly being drawn into the groundwater system.

Monitoring in 2006 of the salinity profile bores in Manly Golf Course, revealed that the saline water which in June of 2006 could be seen at a depth of only $4 \mathrm{~m}$ (EC levels increased from $1006 \mu \mathrm{S} / \mathrm{cm}$ at $4 \mathrm{~m}$ to $3850 \mu \mathrm{S} / \mathrm{cm}$ at $4.5 \mathrm{~m}$ ), had encroached extensively in the six months between testing. In November of 
2006 at the same salinity profile bore at a depth of only $0.5 \mathrm{~m}$ the EC levels were already as high as $2032 \mu \mathrm{S} / \mathrm{cm}$ and steadily increased with bore depth with EC values of $4060 \mu \mathrm{S} / \mathrm{cm}$ at $10 \mathrm{~m}$ in bore depth. If Manly Golf Club continues to overdraw on the groundwater the saline water from the lagoon will continue to increase the EC levels in the aquifer system hence making it unsuitable for irrigation use.

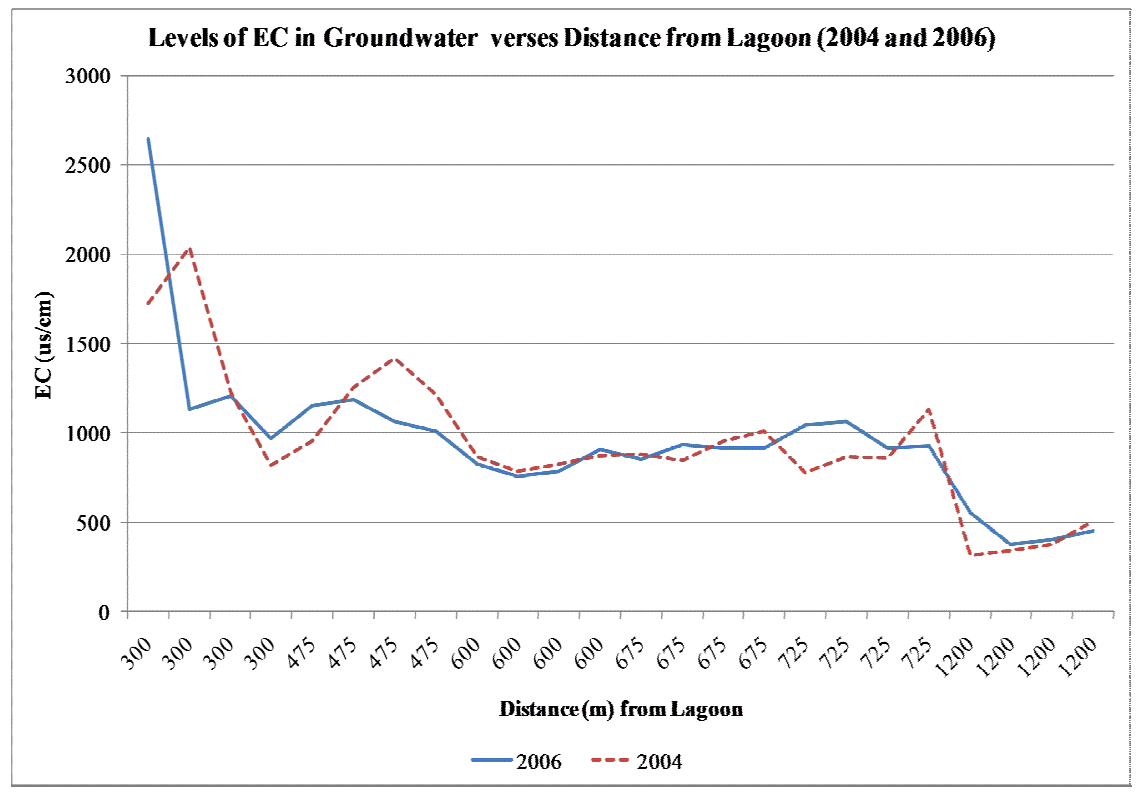

Figure 3: $\quad$ EC Levels in groundwater verses distance from Manly Lagoon.

Manly Council's LM Grahams Reserve bore, which although only established in early 2006, has seen an increase in EC levels (as seen in bold in table 2) between April 2006 and April 2007. An ongoing investigation and monitoring

Table 2: $\quad$ EC Levels in LM Grahams bore 2004-2008.

\begin{tabular}{|c|c|}
\hline \multicolumn{2}{|c|}{ LM Graham Extraction Bore $(\mathrm{EC}-\mu \mathrm{S} / \mathrm{cm})$} \\
\hline Date & Bore \\
\hline $\mathbf{7 / 0 4 / 2 0 0 6}$ & $\mathbf{1 0 9 2}$ \\
\hline $\mathbf{6 / 0 9 / 2 0 0 6}$ & $\mathbf{9 4 7}$ \\
\hline $\mathbf{2 6 / 0 4 / 2 0 0 7}$ & $\mathbf{1 5 2 3}$ \\
\hline $3 / 01 / 2008$ & 1431 \\
\hline $10 / 01 / 2008$ & 1450 \\
\hline $18 / 01 / 2008$ & 1226 \\
\hline
\end{tabular}


regime by Manly Council commenced in late 2007 in an attempt to determine why the EC levels were increasing. The investigation by Council determined that the LM Graham bore had been over extracted by the councils own parks and garden team for use elsewhere in the LGA [9]. This has led Council to reduce the amount of groundwater being extracted from the bore from 132,330L/week to $27,500 \mathrm{~L} /$ week. Since that time the EC levels in the groundwater appear to be deceasing (as seen in italics in table 2) [9].

\subsection{Stormwater data collection}

Stormwater has been monitored by Manly Council on an irregular basis since 2005 from the Cemetery Creek Catchment which runs through Manly Golf Course into Manly Lagoon. Monitoring data obtained from Manly Council indicates that Stormwater running through the Cemetery Creek Catchment has low EC levels (all below $376 \mu \mathrm{S} / \mathrm{cm}$ ). However, the Total Nitrogen (TN) and Total Phosphorus (TP) levels were elevated, regularly falling outside of the irrigation guidelines for Long Term Trigger Values (LTV) (as seen in table 3). The TN levels were compliant $95 \%$ of the time with the irrigation guidelines [7] except for a few events where the TN levels increased to as high as $182 \mathrm{mg} / \mathrm{L}$.

Table 3: $\quad$ TP and TN levels verses ANZECC [7] guidelines.

\begin{tabular}{|c|c|c|c|c|}
\hline \multicolumn{5}{|c|}{ TP and TN levels within Cemetery Creek Stormwater } \\
\hline & $\begin{array}{c}\text { Min } \\
(\mathrm{mg} / \mathrm{L})\end{array}$ & $\begin{array}{c}\text { Max } \\
(\mathrm{mg} / \mathrm{L})\end{array}$ & $\begin{array}{c}\text { Mean }(\mathrm{mg} / \mathrm{L}) \\
\mathrm{N}=33\end{array}$ & $\begin{array}{c}\text { ANZECC [7] Guidelines } \\
(\mathrm{LTV})(\mathrm{mg} / \mathrm{L})\end{array}$ \\
\hline TP & 0.1 & 0.85 & 1.1 & $<0.05$ \\
\hline TN & 0.36 & 182 & 4.9 & 5 \\
\hline
\end{tabular}

\subsection{Manly Lagoon monitoring}

Monitoring of Manly Lagoon over a one year period (2006) indicated that this lagoon was an exceedingly degraded environment. The monitoring identified that the lagoon was severely stressed with elevated levels of heavy metals, and during rain events there is evidence of faecal coliforms entering the waterway. In addition to the heavy metals and faecal coliforms there were also elevated levels of TN and TP.

The lagoon's overall water quality health was also considerably degraded. The basic parameters which can give a straightforward indication of the current situation including $\mathrm{pH}$, dissolved oxygen (DO), turbidity, electrical conductivity and temperature. The data collected during the study showed that the lagoons DO levels were outside the ANZECC [6] water quality guidelines for the protection of aquatic ecosystems the majority of the time (see table 4).

Comparing the water quality of Manly Lagoon with the ANZECC [6] water quality guidelines for the protection of aquatic ecosystems illustrated the fragile state of the receiving environment that could be further influenced/ degraded through the introduction of alternative water sources into the current system [10]. 
Table 4: $\quad$ DO levels recorded in Manly Lagoon 2006-2007.

\begin{tabular}{|c|c|c|c|}
\hline \multicolumn{3}{|c|}{ Dissolved Oxygen (DO) levels recorded in Manly Lagoon 2006-2007 } \\
\hline $\begin{array}{c}\text { Lowest level } \\
\text { recorded }\end{array}$ & $\begin{array}{c}\text { Highest level } \\
\text { recorded }\end{array}$ & $\begin{array}{c}\text { Mean DO level } \\
\mathrm{N}=156\end{array}$ & $\begin{array}{c}\text { ANZECC [6] } \\
\text { Guidelines for DO }\end{array}$ \\
\hline $1.1 \mathrm{mg} / 1$ & $8.8 \mathrm{mg} / 1$ & $4.7 \mathrm{mg} / 1$ & $>6 \mathrm{mg} / 1$ \\
\hline
\end{tabular}

\section{Discussion}

An increase in the EC levels within the bores in Manly Golf Course may be due in part to the fact that the golf course has unsustainably managed their extraction, often extracting more water out of the bores than the aquifer can recharge. Consequently the groundwater supply cannot meet all the irrigation water needs of the golf course and for 107 days per year, the irrigation demand for the course exceeds the sustainable flow rate for the groundwater aquifer to recharge $[11,12]$.

The increase in the EC levels at both Manly Council Recreational Parks and Manly Golf Club has forced them to think about supplementing their groundwater supplies for irrigation with alternative water sources such as stormwater and treated effluent.

The elevated nutrient readings in the stormwater illustrates the uncontrollable nature of stormwater quality that will have to be regularly monitored for quality control and have appropriate safeguards put in place to prevent $\mathrm{TN}$ and $\mathrm{TP}$ nutrients moving through the system into the fragile Manly Lagoon.

It is clear through comparing the quality of Manly Lagoon with the ANZECC [6] guidelines for the protection of aquatic ecosystems, that the lagoon was a very degraded receiving environment. Therefore the proposed alternative water sources for the irrigation of Manly Golf Course, LM Grahams and Keirle Park must not impact on the lagoon through runoff nor seepage into the lagoon. Through utilising system analysis techniques the connectivity of the Manly Lagoon system in relation to the hydro-ecological system were explored as a means of identifying if any problems may arise from the introduction of the different sources of water into this already fragile system.

\section{Conclusion}

Research over the past two years to obtain data relating to the quality of three types of alternative water sources: stormwater, groundwater and treated effluent for irrigation on three urban spaces was undertaken. Results from monitoring and data collection on both the alternative water sources and the receiving environment (Manly Lagoon) indicate that the quality of the alternative water would pose a risk to the local environment including the estuarine influenced groundwater and surface water systems surrounding the three study sites. The research illustrated that the hydro-ecological system surrounding the Manly area is quite complex and fragile, and as such needs to be constantly monitored to 
assess whether the system has adapted positively to the introduction of these new sources of water.

The research also indicated that there needs to be appropriate safeguards in place in order to minimise the variability of the quality of these water sources such as the stormwater to ensure no contamination events enter Manly lagoon. If these safeguards are installed and regular monitoring of the systems adaption to the new water sources are in place these alternative water sources could improve the availability of irrigation water and help improve the local water cycle process of urbanised catchments.

\section{References}

[1] New South Wales Government, 2006 Metropolitan Water Plan, New South Wales Government: Sydney, pp. 17-22, 29-50, 2006.

[2] Manly Council. 2006-2009 Management Plan. Adopted 19 June 2006, Manly Council: Manly, pp. 90-95, 2006.

[3] Morris, C., Water Supply Needs. Formal Discussion Document. GHD: Sydney, 1998.

[4] Galloway, M., Urban Stormwater Pollutant Concentrations, Annual Loads and Current Treatment Train Success in Three Sydney Sub-catchments. The University of New South Wales: Sydney, p. 10, 2005.

[5] Manly Environment Centre., The Restoration of Manly (Queenscliff) Lagoon website, Manly, http://www.mec.org.au/water/index.html .

[6] Australian and New Zealand Environment and Conservation Council (ANZECC). Australian and New Zealand Environment and Conservation Council Guidelines for the Protection of Aquatic Ecosystems, Australian and New Zealand Environment and Conservation Council: Canberra, 2000.

[7] Australian and New Zealand Environment and Conservation Council (ANZECC). Australian and New Zealand Environment and Conservation Council Guidelines for Irrigation, Australian and New Zealand Environment and Conservation Council: Canberra, 2000.

[8] Flood, R. L., Rethinking the Fifth Discipline: Learning within the Unknowable, Routledge: London, 1999.

[9] Galloway, M. Personal Communication, 10 January 2008, Catchment Project Officer, Manly Council, Manly, Australia.

[10] Schwecke. M., Understanding Issues of Irrigating Urban Playing Fields with Alternative Water Sources through Systems Approach. Proc. of the $11^{\text {th }}$ Int. Conf. on Environmental Research Event, eds. P. Pulley, J. Carmody \& K. Venkatraman, Environmental Research Event 2007 Organising Committee: Cairns, Australia, pp. 235-243, 2007.

[11] Patterson Britton and Partners. Manly Golf Course Water Storage, Soil and Groundwater Investigation Including Implications and Way Forwards. Issue no.2 April 2005, Patterson Britton and Partners Pty Ltd: North Sydney, 2005.

[12] Bradbury, M., Minutes from Meeting with Manly Golf Club and Manly Council to discuss water source options for Manly Golf Course. Manly Golf Club Ltd: Manly, 2003. 